\title{
Editorial comment on: 'Colonoscopic perforations: Single center experience and review of the literature'
}

\author{
Erdinç Kamer, Serkan Karaisli
}

\begin{abstract}
-
Dear Editor,

We read the article on "Colonoscopic perforations: Single center experience and review of the literature" by Çolak et al. (1) with great interest.

Colonoscopy is the most effective diagnostic method for colorectal lesions because it allows direct visualization of the colorectal mucosa, it is also the standard procedure for colorectal cancer screening (2). Since early recognition and removal of colorectal polyps are very important in the prevention of colorectal cancer, the use of colonoscopy has increased over the years. Although colonoscopy is a safe procedure, fatal complications such as perforation or bleeding may occur during the procedure. The authors presented their clinical experience on colonoscopic perforation, one of the most serious complications of colonoscopy, in the light of the literature. First, we believe that the addition of some parameters such as ASA score, body mass index, history of abdominal surgery, colonoscopy indications (polypectomy, screening, gastrointestinal symptoms), detected colorectal pathology, time to diagnosis (during colonoscopy, delayed), peritoneal findings, leukocytosis, management (operative, non-operative) and length of hospital stay (day) of the patients into Table 2 that described the demographic characteristics, localization, diagnosis and treatment of patients with colonoscopic perforation will enlighten readers.

In the material-methods section, the authors stated that they applied "radiological examination" for diagnosis, but they only presented X-ray results in the results part. We are of the opinion that clarifying whether abdominal computerized tomography (CT) was applied (especially in patients with peritoneal irritation findings) and describing CT findings (a CT imagemay be added) if available, will strengthen the article.
\end{abstract}

Cite this paper as:

Kamer E, Karaisli S. Editorial comment on: 'Colonoscopic perforations: Single center experience and review of the literature.' Turk J Surg 2017; 33: 318-319.

Department of General Surgery, İzmir Katip Çelebi University Atatürk Training and Research Hospital, İzmir, Turkey

Address for Correspondence Serkan Karaisli e-mail:skaraisli@hotmail.com

Received: 25.09 .2017 Accepted: 16.10 .2017

CCopyright 2017 by Turkish Surgical Association
Although the title of the article is about colonoscopic perforation, the authors grouped perforations of colonoscopy and rectosigmoidoscopy (RSS) separately in their study (Table 1). We think that the RSS information will not provide an additional contribution to the readers. Likewise, perforation occuring during RSS leads to a question mark in the reader's mind. We also think that it would be useful to clarify the specialty of the endoscopist (surgeon or gastroenterologist) in case of colonoscopic perforation.

The authors declared that "ethics committee approval was not required due to the retrospective nature of the study" in the material-methods section. On the other hand, due to the current legislation and the scientific using of the information of the patients, it is necessary to obtain approval of the ethics committee in all studies that do not require the direct intervention of a physician such as all observational studies, survey studies, retrospective archive scans for file or image records. In this regard, we believe that it would be appropriate to correct the disclosure in order not to mislead the readers.

The authors did not specify the ASA scores of the study group, although they emphasized "the findings from our study showed that patients older than 65 years and those with ASA scores greater than 3 are at higher risk for colonic perforation following therapeutic endoscopy" in the results part. We believe that it is worthwhile authors' sharing their thoughts with the readers about how they have achieved this result.

Peer-review: Externally peer-reviewed.

Author Contributions: Concept - E.K., S.K.; Design - E.K., S.K.; Supervision - E.K., S.K.; Resource -E.K., S.K.; Materials - E.K., S.K.; Data Collection and/or Processing - E.K., S.K.; Analysis and/or Interpretation E.K., S.K.; Literature Search - E.K., S.K.; Writing Manuscript - E.K., S.K.; Critical Reviews - E.K., S.K. 
Conflict of Interest: No conflict of interest was declared by the authors.

Financial Disclosure: The authors declared that this study has received no financial support.

\section{REFERENCES}

1. Çolak Ş, Gürbulak B, Bektaş H, Çakar E, Düzköylü Y, Bayrak S, Güneyi A. Colonoscopic perforations: Single center experience and review of the literature. Turk J Surg 2017; 33: 195-199. [CrossRef]

2. Jung Yun Park, Pyong Wha Choi, Sung Min Jung, and Nam-Hoon Kim. The outcomes of management for colonoscopic perforation: A 12-Year Experience at a Single Institute. Ann Coloproctol 2016; 32: 175-183. [CrossRef]

\section{Authors' reply}

Dear Editor,

Following is the authors' response to the contribution to and criticism of the article titled "Colonoscopic perforations: Single center experience and review of the literature".

As noted by the reader, colonoscopy is a very effective tool in the assessment of colorectal cancer and benign lesions. In addition to the parameters of duration of hospital stay, indication for colonoscopy, colonoscopy findings and time to surgery, all of which were elaborated in the text after Table 2, demographic and medical parameters that the reader have mentioned could be documented in Table 2 .

$X$-ray is the initial radiological test in the evaluation of patients. Of the 13 perforations as a result of colonoscopy, nine were detected during the procedure. Therefore, erect abdominal $\mathrm{X}$-ray and chest X-ray were sufficient to confirm the diagnosis and for preoperative evaluation. Additional radiological tests were not needed for these cases. For the other four patients, because of a recent history of colonoscopy, decision was made according to physical examination. Two patients with signs of acute abdomen underwent emergency surgery following the detection of free air in X-ray.

In addition to X-ray, abdominal CT was utilized for the patient who had polypectomy in the ascending colon and had mild tenderness only, as well as the patient with very poor status that refused surgery.

12 of the 13 cases of perforation occurred in the sigmoid colon, rectosigmoid junction or the rectum, which constitute the area of investigation of rectosigmoidoscopy. Only one perforation was from the ascending colon. Although all cases of perforation were patients for whom colonoscopy was planned, no perforations developed for the young patients who underwent rectosigmoidoscopy for rectal hemorrhage. This shows that age and accompanying diseases are important risk factors for perforation.

Colonoscopies were performed by 27 endoscopists of which 24 were general surgeons and 3 were gastroenterologists. Perforations happened during the procedures of ten general surgeons and two gastroenterologists. The rate of perforation for the two groups did not differ significantly.

Perforations occurred in 12 diagnostic colonoscopies and one therapeutic colonoscopy. The mean age was 65.13 years for the diagnostic group and 45 for the therapeutic group. The ASA (American Society of Anesthesiologists) score was not stated in the article, however, the mean length of hospital stay being 15 days (from four to 45 days) suggests a high ASA score.

"Research ethics have become universal in their principles through international treaties. The standardization of regulations facilitates the internationalization of research on drugs. However, for observational studies (i.e. data collected either retrospectively or prospectively, without any therapeutic procedures or follow up in addition to how the patients would otherwise be managed) the modalities used for applying the main principles vary from one country to another." (1) In our country, according to the regulation on clinical research effective since 2014, for retrospective studies utilizing data collected from medical records, approval of the ethics committee is not mandatory. On the other hand, we agree with the reader that it would have been better to obtain ethics committee approval.

\section{Şükrü Çolak}

Clinic of General Surgery, İstanbul Training and Research Hospital, İstanbul, Turkey

\section{REFERENCES}

1. Claudot F, Alla F, Fresson J, Calvez T, Coudane H, Bonaïti-Pellié C. Ethics and observational studies in medical research: various rules in a common framework. Int J Epidemiol 2009; 38: 1104-1108. [CrossRef]

DOI: 10.5152/turkjsurg.2017.3995017 